Entrevista a Nelly Minyersky (por Karina Andriola)Derecho y Ciencias Sociales. Octubre 2018. No 19. (Las familias y el derecho de las familias a dos años de vigencia del Código Civil y Comercial) Pgs 138-149. ISNN 18522971. Instituto de Cultura Jurídica y Maestría en Sociología Jurídica. FCJ y S. UNLP

\title{
El derecho de las familias a tres años de la vigencia del Código Civil y Comercial
}

\author{
Entrevista a Nelly Minyersky (por Karina Andriola) ${ }^{1}$
}

KA: ¿Cuentenos quién es Nelly Minyersky?

NM: Soy Nelly Minyersky, abogada, profesora consulta de la Facultad de Derecho de la UBA y actualmente dirijo una Maestría en Problemáticas sociales infanto-juveniles que es interdisciplinaria, se dicta en la Facultad de Derecho de la UBA, pero es de gestión conjunta entre la Facultad de Derecho, Psicología, Sociales, Medicina y Filosofía y Letras. Tengo una militancia, podemos decir así, en la Campaña por el Derecho al Aborto legal, seguro y gratuito. He trabajado siempre, he estado en la cátedra como profesora de Derecho de Familia, participe en asesoramiento, redacción y critica de muchas leyes de familia y tuve el honor de participar en la comisión redactora del nuevo Código Civil y Comercial.

KA: El Código Civil y Comercial lleva un poco más de tres años de vigencia ¿Qué opinión tiene sobre las discusiones previas y el período de su vigencia?

NM: La historia del Derecho de Familia es una historia que está íntimamente unida a los derechos o la falta de derechos de las mujeres y de los niños. Cuando a mi me preguntan si soy feminista, digo que no sé si soy feminista, lo que sé es que a través del estudio del derecho de familia fui advirtiendo las situaciones desventajosas en que a través de la historia han estado mujeres y niños. Se nota patentemente, nos hemos encontrado con una historia de familia de tipo patriarcal, en el que las mujeres y los niños, son como dos universo a los cuales se los consideraban inferiores ya que el propio Código Civil de Vélez, establecía la categoría de incapaces para estas personas. Había una presunción de que un sector importante de la humanidad, era diferente, pero una diversidad que se traducía en la desigualdad, porque podemos hablar de la igualdad en la diversidad o la diversidad en la igualdad. Eso también, me llevó a observar, cómo en general las leyes que se impulsaron, para lograr ir limando esa brecha en los derechos, esa

\footnotetext{
${ }^{1}$ La presente entrevista fue realizada por personalmente a fecha 21 de septiembre de 2018
} 
Entrevista a Nelly Minyersky (por Karina Andriola)Derecho y Ciencias Sociales. Octubre 2018. No 19. (Las familias y el derecho de las familias a dos años de vigencia del Código Civil y Comercial) Pgs 138-149. ISNN 18522971. Instituto de Cultura Jurídica y Maestría en Sociología Jurídica. FCJ y S. UNLP

discriminación hacia la mujer (la mujer casada en el código de Vélez especialmente) siempre tuvieron mucha dificultad en ser sancionadas y se sancionaron siempre con algún grado de imperfección, una técnica legislativa tal que hacía que estas leyes fueran poco efectivas y eficaces. Si nosotros vemos en paralelo el derecho de la familia y la historia de los derechos humanos, vemos como la universalización de los derechos humanos influyen benéficamente en el derecho de familia.

Por los cambios en la sociedad, en la ciencia, los avances, van modificando el rol de la mujer, aparte la propia historia. Nosotros tenemos que recordar que en el siglo pasado hubo dos guerras muy importantes que asolaron con lo que podría ser el mundo occidental y que también provocaron la incorporación de las mujeres en una serie de tareas que antes le estaban vedadas, esa irrupción de las mujeres en la industria, en el trabajo, ese lugar que tuvieron que ocupar porque los hombres estaban en la guerra, provocó una serie de modificaciones sociales. Después de esas dos tragedias que sufrió la humanidad, pero sobre todo después de la segunda guerra mundial, yo digo que los Estados sintieron la necesidad imperiosa de saber cómo surgía un nuevo tratado de Derechos Humanos, nuevos tratados de derecho internacional, que no se refirieron a guerras, agresión, no agresión. O sea, que no se limitara a las relaciones entre los Estados, sino lo que procuran es que dentro de esos Estados se proteja a los derechos humanos de sus integrantes. Entonces el compromiso es entre Estados que se obliga a respetar los derechos humanos que esos tratados lentamente van incorporando.

Comienzan los tratados de derechos civiles, de derechos políticos, que cada vez amplían el objetivo de estos tratados y en este devenir de ampliación y de universalización de los derechos humanos, empieza a aparecer que los derechos humanos no son los derechos humanos de los hombres, ni para los hombres nada más, sino que las mujeres tienen que estar comprendidas y así comienzan las conferencias mundiales sobre la mujer, se dictan los tratados más importantes. A mi modo de ver, son la Convención sobre la Eliminación de toda forma de Discriminación contra la Mujer (CEDAW) y la Convención de los Derechos del Niño. Mientras en paralelo pasa esto a nivel internacional, nosotros vemos que en nuestro Código Civil de 1871, como dije antes los niños y las mujeres eran totalmente incapaces. Pero hay que dejar en claro que son las mujeres casadas las que tenían ese problema de la incapacidad en el Código de Vélez. Lentamente, a raíz de cambios sociales y políticos, los diputados y legisladores socialistas como Alfredo Palacios, en los parlamentos, empiezan a ampliar derechos, 
Entrevista a Nelly Minyersky (por Karina Andriola)Derecho y Ciencias Sociales. Octubre 2018. No 19. (Las familias y el derecho de las familias a dos años de vigencia del Código Civil y Comercial) Pgs 138-149. ISNN 18522971. Instituto de Cultura Jurídica y Maestría en Sociología Jurídica. FCJ y S. UNLP

pero siempre con mucha dificultad. En el Código Civil, el matrimonio era religioso, y recién en 1888 con la ley 2393 pasa a ser matrimonio civil es un avance muy importante y no fue fácil obtenerla. Los derechos que se amplían en esa ley son prácticamente nulos, y con respecto a la mujer casada ninguno, algo más con la mujer soltera que tenía pocas limitaciones. Siguiendo esa evolución, en 1926 se dicta la ley 11.357 de los Derechos Civiles de la Mujer que si bien amplía sus derechos en la práctica tenía una redacción sumamente confusa porque el marido seguía siendo el administrador presunto de los bienes de la mujer, y la mujer, para que no existiera esa presunción tenía que expresar su oposición en el registro de mandatos. Prácticamente esa ley no hizo demasiado por los derechos de la mujer.

Recién adquirimos una capacidad mejor, más completa, con la ley 17.711 de 1968, que es de la época de Onganía, es uno de los pocos ejemplos de que una ley beneficia a la mujer en época de una dictadura. Eso se dio a esos azares de la vida, por que el doctor Borda, que era ministro de Justicia de Onganía era un liberal, pero un liberal de los que eso ahora casi no hay, era un hombre en cierto modo sensato. Él había sido juez, había observado la inutilidad del divorcio por culpa, e introduce por primera vez un divorcio sanción y le da plena capacidad civil a la mujer casada. Al mismo tiempo, empiezan a producirse pocos años después los tratados internacionales y la Argentina va ratificando estos tratados aunque los cambios en la legislación de derecho de Familia empiezan con la ley 23.264 que se refería a la patria potestad y filiación y la ley 23.515 que introduce el divorcio vincular, o sea no es que nos quedamos totalmente en la rémora del código de Vélez.

Lo cierto, en este panorama es que los jueces no conocían mucho los tratados de Derechos Humanos, no los invocaban, los abogados tampoco invocábamos los tratados que ya teníamos ratificados. Para poner un ejemplo, algunas colegas procuramos que en la ley de matrimonio 23515, se pusiera la equiparación de roles en el matrimonio, y no lo logramos. Siempre estamos como avanzando, pero todavía en la ley 23.264 la mujeres no podíamos impugnar la filiación matrimonial, o sea una mujer casada no podía impugnar la filiación paterna. Entonces, siempre nos faltaba algo, avanzábamos pero no había una adecuación.

Eso en familia, en materia de infancia estuvimos casi peor, tuvimos una contradicción y una fractura entre la realidad y las leyes, por un lado teníamos Código Civil, por otro lado teníamos una rémora, una ley de infancia que era de 1919 que era la ley 10903 que 
Entrevista a Nelly Minyersky (por Karina Andriola)Derecho y Ciencias Sociales. Octubre 2018. No 19. (Las familias y el derecho de las familias a dos años de vigencia del Código Civil y Comercial) Pgs 138-149. ISNN 18522971. Instituto de Cultura Jurídica y Maestría en Sociología Jurídica. FCJ y S. UNLP

era la Ley de Patronato de Menores, donde teníamos una tutela y los niños eran prácticamente objeto, donde tenía hasta descalificaciones a raíz de la pobreza, tenía una ideología muy retrograda y teníamos a su vez la Convención de Derechos del Niño. Ante ello no lográbamos que el parlamento dictará una ley de niñez adecuada a la Convención de Derechos del Niño. En un país como en nuestro, amplio, dilatado, no siempre el juez tiene presente, ni los abogados tampoco, que no regía ya la Ley del Patronato de Menores frente a un tratado, que era superior. Entonces, todos los avances que en la teoría consideran al niño desde la protección integral, como un sujeto de derechos, tenía una fractura, de confusión de leyes.

Otro hito muy importante, 1994 el año que se reúne la Convención Constituyente incorpora a la Constitución Nacional los once tratados de derechos humanos al bloque de constitucionalidad. Si bien ya eran normas superiores, eso le da un impulso, le da como una potencia mayor, pero, si bien estaban en la Convención de Derechos del Niño, nuestras leyes no estaban totalmente adecuadas, y además, con prejuicios, doctrinarios y dogmáticos. La ley 26.061, fue muy criticada por la doctrina, no fue aceptada por muchos supuestos de avances, entonces cómo nos faltaba todavía para hacer más operativa la Convención de Derechos del Niño, también estaba la CEDAW.

El derecho de familia, realmente tuvo un cambio, primero no se puede hablar más de un derecho de la familia, sino de las familias, porque las familias son múltiples, además necesitamos con claridad que la igualdad que proclama la CEDAW estuviera presente en la legislación, que sacáramos los estereotipos. Entonces para que se hiciera operativa, llegará a la realidad, y que fuera más eficaz la Convención de Derechos del Niño, la CEDAW y los tratados del art. 75 inc. 22 de la Constitución Nacional, necesitábamos leyes se acerquen más, como que bajen a la realidad estos tratados, para los abogados y para los jueces. Porque yo creo que en familia era una urgencia.

En sociedad conyugal había una cantidad enorme de normas que no se aplicaba, algunas estaban derogadas expresamente, otras estaban derogadas tácitamente, porque no se usaban pero seguían escritas, tanto que por ahí aparecía la dote o el consentimiento. Entonces creo que en familia, creo que era muy necesario que se dictaran nuevas normas de un código de fondo, que estuviera de acuerdo a estos nuevos tipos de familias, más democráticas. Digo siempre, que el código de Vélez conformó una familia patriarcal y el nuevo Código tendría que conformar una familia más democrática, donde ya no existe el cuidado de la institución familiar, porque la institución familiar no 
Entrevista a Nelly Minyersky (por Karina Andriola)Derecho y Ciencias Sociales. Octubre 2018. No 19. (Las familias y el derecho de las familias a dos años de vigencia del Código Civil y Comercial) Pgs 138-149. ISNN 18522971. Instituto de Cultura Jurídica y Maestría en Sociología Jurídica. FCJ y S. UNLP

existe, existen personas, seres humanos con proyectos de vida en común, que el Código puede denominar familia. Nos interesa el respeto de esos seres humanos en su articulación recíproca, o sea que se propiciara una igualdad y un respeto muy grande entre todos. Creo que el Código Civil y Comercial, cuando se refiere a esos temas, logró ese objetivo.

Ahora tendríamos que ver cómo esas normas se apliquen, como los jueces las incorporen, que incorporen realmente la CEDAW en sus elucubraciones y, yo creo que eso está pasando. Quería hablar con algunas juezas a ver qué piensan de este avances, y también estuve buscando jurisprudencia última y noto que se cita más la CEDAW, en relación a cómo se distribuyen los cuidados personales, a cómo se determina una cuota de alimentos. Se valora, no ya por jurisprudencia, sino porque la ley lo dice, los cuidados personales. Se avanzó muchísimo, pienso que a veces, cuando se trata de derechos humanos lo redundante no importa. No sé si te acordas, pero en la 26061, en su artículo 2, decía, "se declara de aplicación obligatoria la Convención de los Derechos del Niño". El Código nuevo, en los artículos 1 y 2, se refiere a los tratados de derechos Humanos. Algunos dicen, los que creen en la pureza y ¿para qué, si ya lo sabemos, hay tantas cosas formales que te lo recuerdan?.

El primer artículo del código es un gran acierto, como es un gran acierto el art. 402 sobre interpretación y aplicación de las normas que establece que "Ninguna norma puede ser interpretada ni aplicada en el sentido de limitar, restringir, excluir o suprimir la igualdad de derechos y obligaciones de los integrantes del matrimonio, y los efectos que éste produce, sea constituido por personas de distinto o igual sexo”. Ósea acá tenemos la equiparación de roles, eso son caminos, yo creo que en relación a los derechos de la mujer, el código, que tuvo un azar en su redacción, porque este código, te llamaba te decían vos con fulana y fulana este tema, no tenías idea de que se estaba haciendo. Yo tuve el gusto de trabajar con Marisa Herrera y Cecilia Grossman en filiación y responsabilidad parental.

KA: Temas sobre los cuales se abrieron los mayores debates, ataques, críticas

NM: Si, pero como sucede con todas las leyes. Tengo una suerte muy grande, que al ser más vieja, he vivido como se critican y atacan las leyes, pero se imponen. Lo que pasa es que tendríamos que trabajar más en difundirlas, que la gente se empodere, porque el 
Entrevista a Nelly Minyersky (por Karina Andriola)Derecho y Ciencias Sociales. Octubre 2018. No 19. (Las familias y el derecho de las familias a dos años de vigencia del Código Civil y Comercial) Pgs 138-149. ISNN 18522971. Instituto de Cultura Jurídica y Maestría en Sociología Jurídica. FCJ y S. UNLP

derecho de familia no es solamente el conflicto, que eso siempre me preocupa mucho, Díaz Picasso dice que el derecho de familia existe cuando se pelea en tribunales. Yo pienso que no, el derecho de familia lo vivimos todos los días y que tendríamos que lograr, que todas estas cosas nuevas que tiene el código, se conozcan y se trabajen para que el código marque conducta también y no solo lo que va a salir de tribunales. Porque si vos estás hablando de una forma distinta de relaciones, de responsabilidad parental, esa nueva forma no es nada más cuando va a discutir un chico de clase media, una familia, habría que tratar de transmitir, porque creo que hay un cambio sustancial. Porque acá el código, en responsabilidad parental, asumió realmente que el niño es un sujeto de derechos. Para que no queda acá, necesitaríamos que los conozcan los jueces, si lo pudiéramos transmitir estas nuevas formas de relación a muchos sectores, sería bueno. Porque el modelo patriarcal, de malos tratos, se transmitió de algunas formas ya que estaban permitidos en el código de Vélez, entonces ¿cómo podemos cambiar esos modelos y transmitirlos?. Creo que también tendría que ser una función del derecho, de las facultades del derecho. No solo el derecho para el día que se pelean en tribunales, porque el derecho de familia lo vivimos todos los días.

KA: Desde que empezó el proceso de elaboración del CCyC se introdujo como parte del debate la dimensión género y las desigualdades. ¿Qué piensa de la relación entre la normativa y la realidad en la que viven las mujeres?

NM:¿En que avanzó este código en relación a las mujeres?. Bueno, el artículo 402 es una norma que ratifica que hay que trabajar con la CEDAW, con la Convención Interamericana para prevenir, sancionar y erradicar la violencia contra la mujer de Belén de Para, con todos los tratados que tiene que ver con derechos humanos de las mujeres, y sobre todo, los jueces tienen que fallar con una mirada de género. ¿Y qué quiere decir esto?, que hay que pensar en muchos aspectos al momento de interpretar y aplicar el derecho. Se tiene que pensar dónde está la mujer, que las mujeres somos más vulnerables (no siempre), pensar qué paso con esta mujer y no limitarse a un expediente. Otra cosa que tendríamos que tener, es para los temas judiciales una justicia mucho más personalizada y no un procedimiento por escrito. Ahora ¿en que avanzó concretamente? Avanza concretamente en varias instituciones, en relación a los derechos de las mujeres. Una muy importante -para mí no es tanto- es el tema del nombre, del apellido. Cuando 
Entrevista a Nelly Minyersky (por Karina Andriola)Derecho y Ciencias Sociales. Octubre 2018. No 19. (Las familias y el derecho de las familias a dos años de vigencia del Código Civil y Comercial) Pgs 138-149. ISNN 18522971. Instituto de Cultura Jurídica y Maestría en Sociología Jurídica. FCJ y S. UNLP

se autoriza, se permite la elección del apellido, se da un símbolo de igualdad. No es lo mismo que yo me casaba y era "de" aunque después la ley cambió y no era obligatorio, pero la sociedad, en el imaginario social quedó. Ahora con este cambio que se puede poner el apellido, de la mujer, del hombre o el de ambos en el orden que prefieran es un cambio fundamental. Que a lo mejor no vas a ver sus frutos dentro de un año o de cinco años, pero son avances ¿Que tenemos de interesante?

Entre todos los cambios que respectan a las mujeres, tenemos de interesante que por primera vez, en varias instituciones del derecho de familia se nos toma en cuenta como seres humanos, vulnerables, que hemos producido durante años y hemos contribuido al producto bruto del país con el cuidado de los hijos. Entonces cuando se fijan alimentos, todavía durante el matrimonio y se tienen en cuenta todos esos aspectos, factores, quien se ocupó del cuidado personal, si contribuyó con los negocios del marido, que pasó, si tuvo que dejar sus estudios, esos ítems, que estoy diciendo más o menos importantes y adquieren una importancia mucho más grandes cuando se fijan en esta nueva institución, compensación económica, que tiene que ver con el desequilibrio que ocasiona el divorcio, que generalmente perjudican a la mujer y estos ítems generalmente se tienen en cuenta.

La jurisprudencia todavía tiene mucho para trabajar porque no está claro cómo se va a considerar, qué valor tiene, cómo se evalúa haber dedicado 20 años de la vida a cuidar los hijos, haber dejado los estudios universitarios, haber contribuido en los negocios del señor. Yo creo que estos ítems tienen un valor muy importante. También tiene un valor simbólico, cuando en materia alimentos, se dice que los cuidados personales tienen un valor económico, o sea quien está a cargo de los hijos, eso se reconoce en el art. 660 y tiene un valor, también es un valor simbólico muy importante, que el cuidado de los chicos no es algo gratuito. Si bien la mujeres tenemos que contribuir en los alimentos, que también estoy de acuerdo -en la medida de nuestras posibilidades-, si encima además de contribuir, (si tenemos un sueldo) también nos tiene que compensar. A veces no es tanto el tiempo, sino que es la cabeza, las mujeres estamos permanentemente pendientes del cuidado. Entonces, eso me parece a mí, es un cambio fundamental. Otro tema muy importante, para mí, en cuanto al tema género, es que esta historia de considerar el cuidado en las cargas de la sociedad conyugal y que genera un crédito en el caso de extinguirse. 
Entrevista a Nelly Minyersky (por Karina Andriola)Derecho y Ciencias Sociales. Octubre 2018. No 19. (Las familias y el derecho de las familias a dos años de vigencia del Código Civil y Comercial) Pgs 138-149. ISNN 18522971. Instituto de Cultura Jurídica y Maestría en Sociología Jurídica. FCJ y S. UNLP

Después un avance -aunque no todo lo que hubiésemos querido-, es el reconocimiento de la uniones convivenciales, de la uniones de hecho. Tema en el cual la mujer siempre salió muy perjudicada, que por primera vez intento cambiarse. Porque también el derecho te legitima, porque ahora nadie va a hablar de concubinato, vamos cambiando, cambia el lenguaje, entonces es elevar socialmente, en el imaginario, y que ya el Código Civil y Comercial, nos hable de unión convivencial y le reconozca el derecho.

Como incorporamos el tema de las familias, cualquier tipo de familia está comprendida en este código, el código no lo dice, no tiene por qué decirlo, pero al no decirlo también es omnicomprensivo. Entonces no importa si es matrimonio de dos mujeres, de dos hombres, un matrimonio heterosexual. En filiación ya teníamos la equiparación, decidimos incursionar también, era nuestra obligación. Venían miles de niños nacidos por fecundación asistida, aun después de la ley de matrimonio igualitario, que para mí el vínculo filiatorio, en los cuales hay donación de óvulos o espermatozoides. En última instancia nuestra legislación, mientras se mantuvo el tema de que el nacimiento lo acredita el parto de la mujer y los efectos en cuanto a la filiación que de este emergen, el vínculo que no estaba claramente reglado, que una persona que donó el óvulo o una que permitía la fecundación con esperma y aparecía como padre, y podría impugnar con una prueba genética que no era el padre. Lo nuevo que tenemos en el Código es que prácticamente, es exactamente igual los derechos que emanan de la filiación, ya sea adoptiva, por naturaleza o por técnicas de reproducción humanamente asistida.

En filiación, otro avance muy importante, es la posibilidad de que las mujeres impugnen la filiación matrimonial, paterna, que hubo un caso, el de Paez Villaró, que llegó a la Corte donde se le negó a la madre esa posibilidad. Y el Código quiso cambiar eso con niñez, y con adopción, se adoptó una técnica de principios importantes, se mejoró mucho la legislación de adopción. En responsabilidad parental que vemos estos principios que tienen que reglar todo el instituto, que son el derecho del niño a ser oído, la capacidad progresiva, el interés superior del niño. Que estén presentes como principios, al comenzar el capítulo de responsabilidad parental me parece importante, como también me parece muy importante cómo se redactaron, las obligaciones y deberes, ya no es poder de los padres sobre los hijos, es intercambio, el derecho de respetar, que es un artículo que me gusta.

Menciono el artículo 646 "Enumeración: Son deberes de los progenitores: a) cuidar del hijo, convivir con él, prestarle alimentos y educarlo, b) considerar las necesidades 
Entrevista a Nelly Minyersky (por Karina Andriola)Derecho y Ciencias Sociales. Octubre 2018. No 19. (Las familias y el derecho de las familias a dos años de vigencia del Código Civil y Comercial) Pgs 138-149. ISNN 18522971. Instituto de Cultura Jurídica y Maestría en Sociología Jurídica. FCJ y S. UNLP

especificas del hijo según sus características psicofísicas, aptitudes y desarrollo madurativo, c) respetar el derecho del niño y adolescente a ser oído y a participar de su proceso educativo, d) prestar orientación y dirección al hijo para el ejercicio y efectividad de sus derechos, e) respetar y facilitar el derecho del hijo a mantener relaciones personales con abuelos, otros parientes o personas con las cuales tenga un vínculo afectivo.", o sea, es una relación horizontal de articulación de seres humanos, que saca el poder como elemento.

También se introduce un factor, que es muy discutido, y ahí va a haber que trabajar mucho todavía, que es el tema de los cuidados personales compartidos. Merece un capítulo, pero te digo una frase, el cambio que hay en el lenguaje, es una cosa totalmente nueva. Salimos de patria potestad a responsabilidad parental, de tenencia a cuidado personal, y los cuidados personales compartidos, que en realidad yo estoy de acuerdo totalmente, están siendo interpretados, por algunos sectores feministas, no solo acá, sino en otros países. Aquí tenemos que pensar en relación a lo que dice la CEDAW en su capítulo primero, que una ley para ser discriminatoria, no basta con que tenga una discriminación clara, si sus efectos son discriminatorios, entonces es discriminatoria. Otro ejemplo de discriminación por los efectos es el aborto, aparece como no discriminatorio, pero es muy discriminatorio, que pasa lo mismo con los cuidados personales. En algunos países de latinoamericana se percibió, y eso es porque los jueces no fallan con perspectiva de género, que los hombres usaban los cuidados compartidos, o las formas alternadas de tenencias, para no pasar alimentos. Pero eso nuestro código no dice eso, dice que en los casos de cuidados compartidos, que va a contribuir el que tiene mayores posibilidades.

KA: También me dijo que objetaría algo y me gustaría que me hable del proyecto de Ley de interrupción voluntaria del embarazo que no salió, del futuro del derecho de las familias en ese sentido

NM: Aquello que está mal en este código, a pesar de que creo que debo ser la única en decir esto del régimen patrimonial del matrimonio. Lo que tuvo de bueno el código de Vélez Sarfield, fue lo sociedad conyugal, eso fue algo importante para nuestro país, un país de inmigrantes, la ganancialidad era lo bueno, el trabajo, la familia, que venía, se casaba, con un proyecto de vida en común y en ese proyecto de vida en común y lo que 
Entrevista a Nelly Minyersky (por Karina Andriola)Derecho y Ciencias Sociales. Octubre 2018. No 19. (Las familias y el derecho de las familias a dos años de vigencia del Código Civil y Comercial) Pgs 138-149. ISNN 18522971. Instituto de Cultura Jurídica y Maestría en Sociología Jurídica. FCJ y S. UNLP

ingresaba fruto del trabajo era de los dos, o sea se le reconoció a la mujer patrimonialmente cosa que no sucedía en todos los países. Ahora, debido al divorcio vincular, y la objeción de las parejas al momento de contraer nuevo matrimonio, para no estar sometidas nuevamente a la ganancialidad, se introduce el tema de la opción del régimen patrimonial del matrimonio, que puede hacerse al momento del matrimonio o después, por lo cual es una riesgo, porque la mujer en Argentina, no está en condiciones, la mayoría, no tienen el mismo nivel económico, ni la independencia económica de los hombres.

Volviendo a aborto, tenemos unos artículos, que fueron muy invocados, incorrectamente invocados, en el debate reciente, son los art. 19, 20 y 21. Cuando se trabaja con un código civil, sus efectos son para un código civil, sus efectos no tienen por misión decir quien es un ser humano y quién no. Lo que hace el derecho muchas veces es crear ficciones. Entonces dice “ es persona”. El código de Vélez decía, se es persona desde el momento de la concepción, y que el nasciturus tenía algunos derechos y aclaraba después que lo representaban los progenitores, al solo efecto patrimonial. Le preocupaba a Vélez (y que lo escribe en el art. 3290 de su código, en la parte de sucesiones) si el que nacía después de la muerte de quien concibió tenía o no derechos hereditarios, dice en el art. 3290 que realmente adquiere dichos derechos cuando sale del vientre materno. Y en el art. 67 y 70, en los que habla del nasciturus dice que tiene condición la viabilidad, o sea que si no nace con vida es como si no hubiese existido. Entonces, qué dice Vélez cuando nos define a la persona, protege esos derechos hereditarios, pero no le otorga ningún otro derecho, porque cualquier otro derecho está sujeto al nacimiento.

Inclusive el Código Civil y Comercial habla en la parte de alimentos sobre el derecho de la mujer embarazada, quien lo pide para ella, porque el feto, el embrión son totalmente dependiente de quien gesta, no hay otra forma que se alimente que no sea a través de la madre. Y el artículo lo dice claramente, quien alimente, la embarazada, tiene derecho a pedirlo. Cuando por presiones, de determinadas confesiones, el artículo 19 dice "que se es persona desde el momento de la concepción".

A diferencia del texto de Vélez le agregaron la palabra "humanas", pero las personas del código de Vélez eran tan humanas como las de este código. Pero todo esto es porque tienen un propósito. La existencia de la persona comienza se establece en el articulo 19 y en el artículo 20 se habla de la "duración del embarazo y época de la concepción. 
Entrevista a Nelly Minyersky (por Karina Andriola)Derecho y Ciencias Sociales. Octubre 2018. No 19. (Las familias y el derecho de las familias a dos años de vigencia del Código Civil y Comercial) Pgs 138-149. ISNN 18522971. Instituto de Cultura Jurídica y Maestría en Sociología Jurídica. FCJ y S. UNLP

Época de la concepción es el lapso entre el máximo y el mínimo fijados para la duración del embarazo". Postulado absurdo, porque la época de la concepción no tiene un plazo máximo, yo no puedo concebir en el día 170. "Se presume, excepto prueba en contrario, que el máximo de tiempo del embarazo es de trescientos días y el mínimo de ciento ochenta días, excluyendo el día del nacimiento". Así también, el artículo 21 establece que el "Nacimiento con vida. Los derechos y obligaciones del concebido o implantado en la mujer quedan irrevocablemente adquiridos si nace con vida. Si no nace con vida, se considera que la persona nunca existió. El nacimiento con vida se presume".

Primero nos habla de obligaciones, y yo no entiendo qué tipo de obligaciones puede tener el nasciturus, independiente de un derecho, es cierto que si recibe un patrimonio, va a tener las obligaciones si nace con vida. Tanto es así que en la nota del art. 3290 del Código de Vélez dice, que es interesante, en realidad lo que puede tener el nasciturus (ya lo decían los romanos) derechos y no obligaciones, y si tiene una obligación, es porque va a acceder a un derecho. Forzaron una redacción, porque si bien en los fundamentos se dice que el art. 19 sigue al código de Vélez y no se puede considerar que tenga una implicancia con el derecho penal, porque son dos cosas distintas, no tiene nada que ver con que se sancione el aborto. El código civil es para los efectos civiles, estado, domicilio, nombre, el derecho de propiedad.

Entonces esto realmente, tiene un valor simbólico embromado, y te lo introdujeron, y hablan de las dos vidas y no tiene nada que ver, esto no da ningún derecho a pensar que el aborto es inconstitucional. Si me decís que era mejor que dejaran el código civil como estaba o que pongan esto que no nos gusta y otras que si, prefiero el nuevo Código. Igual vamos a seguir diciendo, con este Código y con el de Vélez que el aborto es constitucional. Esto en familia, esto y régimen de separación de bienes son cosas que objeto, pero en general, hay temas que plantea para que los jueces fallen con perspectiva de género.

El artículo 26, me parece un avance enorme, si bien la redacción es confusa, toma la competencia médica de los menores de edad y que reconoce, un derecho humano, tan personalísimo como es el derecho a la salud y al propio cuerpo. Lo he dicho siempre, como se hablaba de un derecho de menores, yo creo que el derecho de familia es para todos, es para la pibita que está en la calle, no es nada más para la clase media o alta, sino ¿Para qué te interesa? Vez cada inutilidad en tribunales, y yo creo que es un dispendio jurisdiccional en algunas cuestiones, habría que pedirle mayor madurez a la 
Entrevista a Nelly Minyersky (por Karina Andriola)Derecho y Ciencias Sociales. Octubre 2018. No 19. (Las familias y el derecho de las familias a dos años de vigencia del Código Civil y Comercial) Pgs 138-149. ISNN 18522971. Instituto de Cultura Jurídica y Maestría en Sociología Jurídica. FCJ y S. UNLP

gente. Creo que si el derecho nos reconociera, y en la vida, el derecho te da un instrumento, habría menos femicidios, no todas las mujeres se dejan golpear, el cambio social necesita el empoderamiento.

KA: Muchas gracias 